\title{
MAPLE Synthesis of Reduced Graphene Oxide/Silver Nanocomposite Electrodes: Influence of Target Composition and Gas Ambience
}

Albert Queraltó*,1, Ángel Pérez del Pino*,2 ${ }^{*}$ Constantin Logofatu ${ }^{3}$, Angela Datcu ${ }^{1}$, Roger Amade ${ }^{4,5}$, I. Alshaikh $^{4,5}$, Enric Bertran ${ }^{4,5}$, Iuliana Urzica ${ }^{3}$, Enikö György ${ }^{1,2}$

${ }^{1}$ National Institute for Lasers, Plasma and Radiation Physics, PO Box MG 36, 77125 Bucharest, Romania

2 Institut de Ciència de Materials de Barcelona, Consejo Superior de Investigaciones Científicas (ICMAB-CSIC), Campus UAB, 08193 Bellaterra, Catalonia, Spain.

${ }^{3}$ National Institute for Materials Physics, PO Box MG 7, 77125 Bucharest, Romania

${ }^{4}$ Departament de Física Aplicada, Universitat de Barcelona, C/Martí i Franqués 1, 08028 Barcelona, Catalonia, Spain

${ }^{5}$ Institute of Nanoscience and Nanotechnology, IN2UB, Universitat de Barcelona, Catalonia, Spain

* Corresponding Authors:

Dr. Albert Queraltó

Institut of Inorganic Chemistry, University of Cologne, Greinstrasse 6, 50939 Cologne, Germany

Tel. +492214703070

E-mail: albert.queralto.lopez@gmail.com

Dr. Ángel Pérez del Pino

ICMAB - CSIC, Campus UAB, 08193 Bellaterra, Catalonia, Spain

Tel. +34 935801853

E-mail: aperez@icmab.es 
KEYWORDS: graphene oxide nanocomposites, MAPLE, graphene oxide-silver electrode, energy storage

\section{ABSTRACT}

Graphene oxide (GO) and reduced GO films with different amounts of silver nanoparticles (Ag NPs) have been deposited on quartz and silicon substrates by matrix assisted pulsed laser evaporation (MAPLE). The morphology, structure, chemical composition, and optical and electrochemical properties were evaluated by scanning electron microscopy, X-ray photoelectron spectroscopy, ultraviolet-visible spectrophotometry, and cyclic voltammetry measurements. The properties of the films obtained with two types of GO precursors have been compared. A reduction of the amount of oxygen containing groups is observed with the increase of the Ag concentration, which leads to a decrease of the optical band gap. Moreover, the deposition in nitrogen gas ambience leads to the Ndoping of rGO material. The films obtained with the highest amount of Ag and with nitrogen doping show potential to be used in energy storage electrodes.

\section{INTRODUCTION}

Graphene oxide (GO) have attracted great attention due to their remarkable and multiple physicochemical properties such as high chemical reactivity, transparency, and mechanical strength very useful for applications in photocatalysis, energy storage/conversion, electrical transport, etc [1-5]. For instance, it has been reported that GO presents intrinsic and tunable fluorescence in the nearinfrared, visible and ultraviolet range which could be used for applications such as optical sensors for DNA and biomolecules [6, 7]. In addition, thanks to its bandgap tunability which depends on the degree of oxidation, GO could be used as an electrical insulator when it is fully oxidized or as a transparent 
conducting material due to the p-type semiconducting properties exhibited when the amount of oxygen groups is decreased, forming reduced GO (rGO) [8-10]. Interestingly, the particular relation between the oxygen functional groups and carbon arrangements in GO and rGO have also attracted enormous interest for their use in photocatalysis applications such as the conversion of $\mathrm{CO}_{2}$ to methanol or the production of $\mathrm{H}_{2}$ from water splitting [11-13]. Lastly, rGO can be functionalized through the incorporation of nitrogen species conferring different properties such as switching from p- to n-type semiconductor [14]. Besides the interest in standalone GO, there is great attention in the development of GO nanocomposite films with either metal (e.g., $\mathrm{Ni}, \mathrm{Au}$ ) or metal oxides nanoparticles (e.g., $\mathrm{NiO}, \mathrm{TiO}_{2}$, $\mathrm{SnO}_{2}, \mathrm{Fe}_{3} \mathrm{O}_{4}, \mathrm{MnO}_{2}$ ) that combine both the properties of $\mathrm{GO}$ and the nanoparticles (NPs) enhancing their performance for applications in photocatalysis, supercapacitors, electrochemistry, water-splitting, etc [15-23]. Recently, (r)GO-Ag composites are attracting high research interest due to their multifunctional properties and wide range of applications. Thus, films composed of GO platelets decorated with Ag NPs reveal high antibacterial and antifungal properties, so they are being used in filters and disinfection systems [24-27]. Moreover, rGO-Ag hybrids show promise for novel anticancer therapies [28, 29]. The catalytic and photo catalytic activity of these materials allow them to develop innovative electrochemical sensing devices of a plethora of organic and biologic compounds [30-34], as well as hazardous compounds degradation processes [35-37]. It also deserve noting that the specific electric, optic and redox properties of (nitrogen doped) rGO-Ag nanohybrids also exhibit promise to be used in energy generation and storage, as well as electronic devices [38-43].

The fabrication of high-performant devices based on graphene is often difficult since graphene sheets are prone to agglomeration. Despite that, several methods have been developed for the fabrication of graphene-like materials with similar properties to those of pristine graphene through the reduction of GO sheets, which has some residual oxygen-containing functional groups and making it highly dispersible in water. Typically, the fabrication of rGO is based on chemical reduction or thermal treatments [3, 44, 45]. However, these so-called conventional methods are time consuming, imply toxic chemical substances, and high processing temperatures $\left(500-1000{ }^{\circ} \mathrm{C}\right)$. Matrix-assisted pulsed laser 
evaporation (MAPLE) is a laser-based technique that consists of the deposition of a material on a substrate under controlled environment conditions through the irradiation of a previously frozen solution / dispersion which contains the material of interest [46]. This leads to the evaporation of the target's solvent and the deposition of the desired material on a substrate. One can control the film thickness by tuning the number of applied laser pulses. In addition, deposition is often performed at room temperature which enables the use of temperature sensitive substrates such as polymers. For this reason, MAPLE has been extensively employed in the deposition of polymers and biomaterials [47-51]. Moreover, it has also been demonstrated ideal to transfer colloidal nanoparticles, quantum dots, inorganic nanomaterials and carbon nanostructures [52-54]. Thanks to the high dispersibility of GO nanosheets in water, and their relatively high absorbance in the UV range, inverse UV-MAPLE can become an alternative deposition method to the conventional techniques for the synthesis and deposition of hybrid rGO-NPs thin films at room temperature in different ambient conditions, as demonstrated recently $[16,19,55]$.

In spite of all this, the particular composition of GO starting precursor materials, i.e., the amount and type of oxygen functional groups is of vital importance and will likely have a large influence on the final state of the rGO films and their functional properties. Therefore, we have investigated the fabrication of GO/Ag nanocomposite thin films by MAPLE from two different GO precursor materials. We tuned the degree of reduction and nitrogen doping of rGO by modifying the amount of $\mathrm{Ag}$ nanoparticles, the irradiation processing parameters and the irradiation environment. Furthermore, we prove the ability of MAPLE technique for the versatile fabrication of energy storage electrodes with significant volumetric capacitance.

\section{MATERIALS AND METHODS}

GO dispersions were synthesized by mixing GO powder [nanosheets with approximately 15-20 layers and ca. 25\% degree of oxidation from Sigma Aldrich (SA) and nanosheets with 1-4 layers with about 55\% degree of oxidation from NanoInnova (NInn)] with deionized water. The ratio between GO powder 
and water was set to obtain a dispersion with a GO content of 3 wt\% (GO-SA) and 6 wt\% (GO-NInn), respectively, in order to get films with similar final thicknesses of around 40-150 nm. Silver nanoparticles (Ag NPs) with sizes below $100 \mathrm{~nm}$ from Sigma-Aldrich were added into the dispersions with different amounts to achieve $\mathrm{Ag} / \mathrm{GO}$ ratios of $0,1 / 3$, and 1 for each precursor, i.e., the $\mathrm{Ag}$ content was 1 and $3 \mathrm{wt} \%$, and 2 and $6 \mathrm{wt} \%$ for GO-SA and GO-NInn precursors, respectively. The dispersions were stirred and sonicated for 30 min. Immediately after, MAPLE targets were prepared by filling a target holder with the homogeneous dispersion and flash frozen at $77 \mathrm{~K}$ by immersing the target holder in liquid $\mathrm{N}_{2}$.

MAPLE experiments were carried out at room temperature in a stainless steel chamber by irradiating the frozen targets with a Quantel Brilliant B Nd:YAG laser ( $\lambda=266 \mathrm{~nm}, \tau \sim 5 \mathrm{~ns}, v=10 \mathrm{~Hz})$. The chamber was brought to a residual pressure of $10^{-2} \mathrm{~Pa}$ before the laser irradiation. Comparative sets of experiments were done in $\operatorname{Ar}(2 \mathrm{~Pa})$ and $\mathrm{N}_{2}$ (20 Pa). During the experiments, the incident laser beam scanned the target surface at an angle of $45^{\circ}$ and a constant velocity of $1.5 \mathrm{~mm} \mathrm{~s}^{-1}$ over an area of approximately $1 \times 1 \mathrm{~cm}^{2}$. A number of $10^{4}$ laser pulses at a fixed fluence of $0.2 \mathrm{~J} \mathrm{~cm}^{-2}$ were applied for the deposition of each sample. Quartz and silicon substrates of $1 \times 1 \mathrm{~cm}^{2}$ were placed parallel to the target at a separation distance of $5 \mathrm{~cm}$.

The surface morphology of the GO films was investigated with a QUANTA FEI 200 FEG-ESEM scanning electron microscope (SEM). The chemical composition of the precursors and as-deposited GO samples was analyzed by X-ray photoelectron spectroscopy (XPS) with a SPECS XPS spectrometer based on a Phoibos 150 electron energy analyzer. The equipment used a monochromatic X-ray emitter of AlMg Ka $(186.74 \mathrm{eV})$. The electron energy analyzer was operated in the constant energy mode. Extended spectra, over wide ranges of binding energies (1200 eV), were acquired using an analyzer pass energy of $50 \mathrm{eV}$. High resolution spectra were acquired over smaller ranges $(20 \mathrm{eV})$ at $10 \mathrm{eV}$ pass energy with an energy resolution of $0.7 \mathrm{eV}$ (FWHM of the $\mathrm{Ag} 3 \mathrm{~d} 5 / 2$ line). All the measurements were carried out in ultra-high vacuum $\left(\sim 10^{-7} \mathrm{~Pa}\right)$. The C (1s) line (284.6 eV) corresponding to the surface 
adventitious carbon (C-C line bond) was used as reference binding energy. The thickness of GO films was determined with a Stylus Profiler XP-2 profilometer with a vertical resolution of $1.5 \AA$ from Ambios Technology. Optical measurements of the deposited films were carried out using a Shimadzu UV-2600 spectrophotometer with a slit width of $2 \mathrm{~nm}$ and were used to calculate the absorption coefficient $\alpha$. Then, the optical bandgap was obtained applying the Tauc plot method by assuming direct transitions $(n=1 / 2)[56,57]$. The electrochemical properties of the GO-Ag nanocomposite electrodes were studied by means of cyclic voltammetry (CV) in a $1 \mathrm{M} \mathrm{Na}_{2} \mathrm{SO}_{4}$ aqueous solution using a potentionstat/galvanostat (AutoLab, PGSTAT30, USA). All experiments were carried out in a threeelectrode cell at $25^{\circ} \mathrm{C}$ in the dark. $\mathrm{An} \mathrm{Ag} / \mathrm{AgCl}$ electrode (3 $\mathrm{M} \mathrm{KCl}$ internal solution) and a Pt-ring electrode were used as the reference and counter electrode, respectively. The working electrode was a sample of GO-Ag composite which was contacted through the silicon substrate with the current collector from the electrochemical cell using a microwave soldering system. The geometrical area of the working electrode was set to a constant value of $0.57 \mathrm{~cm}^{2}$.

\section{RESULTS AND DISCUSSION}

\subsection{Compositional and structural analysis of GO/Ag nanocomposite films}

Deposited graphene oxide/silver nanocomposite films either from SA or NInn precursors possess similar irregular morphologies. The Ag free GO films have thicknesses of 40-60 nm and RMS roughnesses of 3.5-4.5 nm. Instead, Ag/GO nanocomposite films are thicker with thickenesses ranging from 80 to 150 $\mathrm{nm}$ and RMS roughnesses between 5 and $7.5 \mathrm{~nm}$. Figure 1a,b shows SEM images of the films grown from SA precursors in $\mathrm{N}_{2}$ with a ratio $\mathrm{Ag} / \mathrm{GO}$ of 0 and 1/3, respectively. Equivalent images for NInn precursors can be found in Figure S1. The GO platelets have sizes ranging from approximately $250 \mathrm{~nm}$ to $1 \mu \mathrm{m}$ and are distributed rather homogeneously. Thick aggregates, caused by the accumulation of several GO platelets, are also observed. Backscattered SEM images show that the Ag NPs are randomly distributed on the films (Figure S2) and, in some cases, can have sizes over $200 \mathrm{~nm}$ due to the 
coarsening experienced during the deposition process (Figure S1), whereas the initial NPs dimensions are below $100 \mathrm{~nm}$. The Ag NPs, which initially are larger than the film thickness in some cases, appear to be flattened. This would be caused by the melting of the Ag NPs induced by the laser radiation. Then, the molten Ag NPs crash into the substrate and remain in that form after solidifying. Figure 1c illustrates the surface of a GO film grown in Ar ambience. The lesser amount of GO platelets is likely caused by the lower gas pressure of $2 \mathrm{~Pa}$ used during the experiments which leads to a broader and lighter plume.
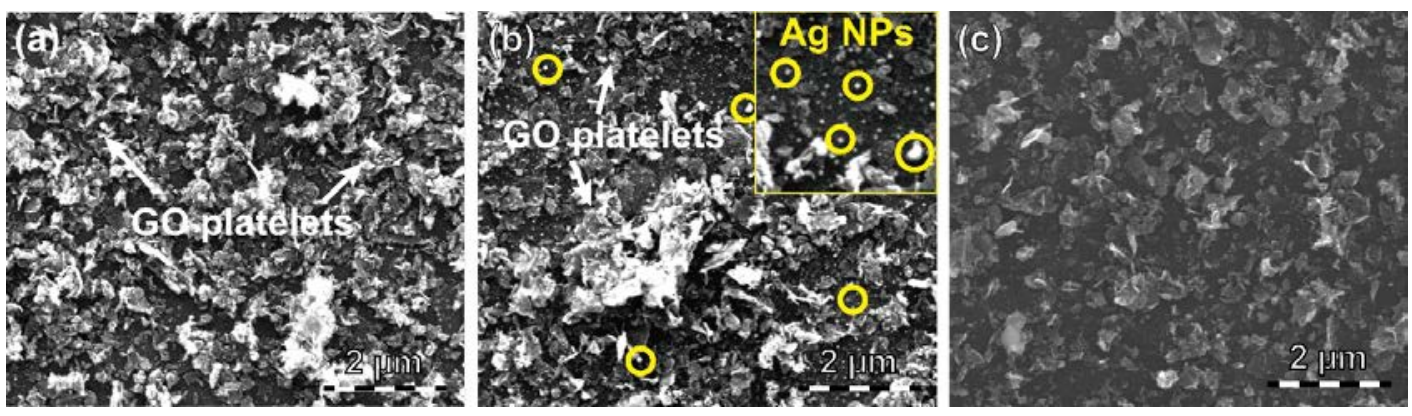

Figure 1. SEM images of (a) GO and (b) GO/Ag nanocomposite films prepared from SA precursors on Si substrates with an $\mathrm{Ag} / \mathrm{GO}$ ratio of $1 / 3$ in $\mathrm{N}_{2}(20 \mathrm{~Pa})$ atmosphere. Inset: zoomed area of the SEM image showing the Ag NPs. (c) Equivalent GO film grown in $\operatorname{Ar}(2 \mathrm{~Pa})$ atmosphere.

XPS analyses have been used to investigate the composition of GO-Ag nanocomposite films. Figure 2a and S3a illustrate the C1s spectrum of the GO powder and dropcasted samples from both SA and NInn precursors, respectively. The spectra have been deconvoluted in five Gaussian peaks: CI, CII, CIII, CIV and CV, centered at 284.6, 285.6, 286.5, $288 \mathrm{eV}$ and $291 \mathrm{eV}$. The CI peak corresponds to the $\mathrm{sp}^{2}$ graphitic carbon-carbon bonds $(\mathrm{C}=\mathrm{C})$. The remaining peaks can be associated to carbon-oxygen functional groups. The CII peak corresponds to single-bonded carbon and oxygen atoms such as epoxy (C-O-C) and hydroxyl (C-OH), while CIII and CIV peaks can be respectively correlated to carbonyl $(\mathrm{C}=\mathrm{O})$ and carboxyl $(\mathrm{COOH})$ groups $[58,59]$. The $\mathrm{CV}$ peak is generally identified as a shake-up satellite related to $\pi-\pi^{*}$ transition [60]. This peak is not detected in the NInn GO dropcasted sample. 
Both powder C1s spectra show that the starting amount of oxygen functional groups is completely different, with a larger content of oxygen groups in the NInn GO precursors.

Figure 2b shows the deconvolution of XPS N1s spectra for the same samples. The spectra can be deconvoluted in two peaks: NI located at $399.7 \mathrm{eV}$ which is associated to amine groups and NII at 402 eV which corresponds to pyridinic $\mathrm{N}-\mathrm{O}$ groups [61, 62]. The latter peak is the less intense in both cases. This indicates that there is already a small amount of nitrogen functional groups in the precursor materials. These N-bearing aliphatic moieties may either be bonded to carbon atoms at graphene backbone or to the O-containing groups. Unfortunately, the carbon-nitrogen groups have binding energies at 285.9 and $287.3 \mathrm{eV}$ which are superposed with those of carbon-oxygen bonds in the C1s signal (peaks CII and CIII). Hence, it is not possible to discern between them [61, 63]. XPS C1s spectra are presented in Figure 3a and 3b for the films with an $\mathrm{Ag} / \mathrm{GO}$ ratio of 1 and, respectively, in $\mathrm{Ar}$ and $\mathrm{N}_{2}$ ambience for both SA and NInn precursors. The XPS spectra for GO and Ag/GO films with 1/3 ratio are reported in Figure S4 and S5 for SA and NInn precursors, respectively. Apparently, the C1s spectra using SA precursors seem quite similar to those of dropcasted samples. On the other hand, the C-O peaks are much less intense in the C1s spectra using NInn precursors, indicating a large reduction process. It is worth noticing the disappearance of the CV peak related to $\pi-\pi^{*}$ transition for SA precursors after MAPLE deposition. However, NInn GO samples show the presence of additional peaks at $\sim 293 \mathrm{eV}$ (CVI) and $\sim 295 \mathrm{eV}$ (CVII) which can be associated to $\pi-\pi^{*}$ transition, or to the presence of quaternary $\mathrm{N}$ atoms on zigzag edges of graphene [64, 65] (Figure 3 and S5). The observed reduction of $\mathrm{GO}$ is caused by the energy deposited by the laser radiation. The photon energy $(4.7 \mathrm{eV})$ is larger than the dissociation energy of the oxygen functional groups, hence, direct photo-dissociation or photochemical reduction is anticipated. In addition, the GO films heat due to the absorption of the laser radiation leading to a photothermal reduction $[55,66]$. 
Figure 3c shows the N1s XPS spectra of the GO-Ag nanocomposite films in which we can identify more intense NI (399.7 eV) and NII (402 eV) peaks. In this case the NI and NII peaks may also show the contribution of pyrrolic and quaternary $\mathrm{N}$ groups, respectively [67]. In addition, we observe the appearance of an additional peak (NIII) at $406 \mathrm{eV}$ which may be associated to the presence of $\mathrm{NO}_{\mathrm{x}}$ bonds or $\pi$ excitations $[68,69]$. Figure S6 shows the Ag3d XPS spectra for a sample deposited in Ar. We can identify a doublet with peaks at approximately 368.2 and $375 \mathrm{eV}$ (AgI and AgII, respectively). These peaks are associated with the electrons of the $A g 3 d_{3 / 2}$ and $A g 3 d_{5 / 2}$ bands which demonstrates the presence of silver in the films [70]. In some samples, there is presence of small satellite peaks that are linked to loss features as reported in the literature [70]. The only appreciable change in the Ag XPS peaks between the different films is the increase of the intensity of the peaks with the amount of Ag. The films obtained in Ar are slightly thinner than those grown in $\mathrm{N}_{2}$ which leads to less material and a slightly lower XPS signal. In contrast, we have a larger Ag signal in the film while increasing the amount of Ag in the target for each $\mathrm{N}_{2}$ and Ar series, as it is observed in Figure S8. The analysis of the O1s XPS spectra (Figure S7 and S8) shows that it can be deconvoluted in 3 peaks corresponding to the C-O and $\mathrm{C}=\mathrm{O}$ bonds at 532 and $533.5 \mathrm{eV}$ [71], respectively, and an additional peak at $531.6 \mathrm{eV}$ which can be attributed to $\mathrm{Ag}_{2} \mathrm{O}[72,73]$. Therefore, this indicates that the $\mathrm{Ag}$ is partially oxidized. 
(a)

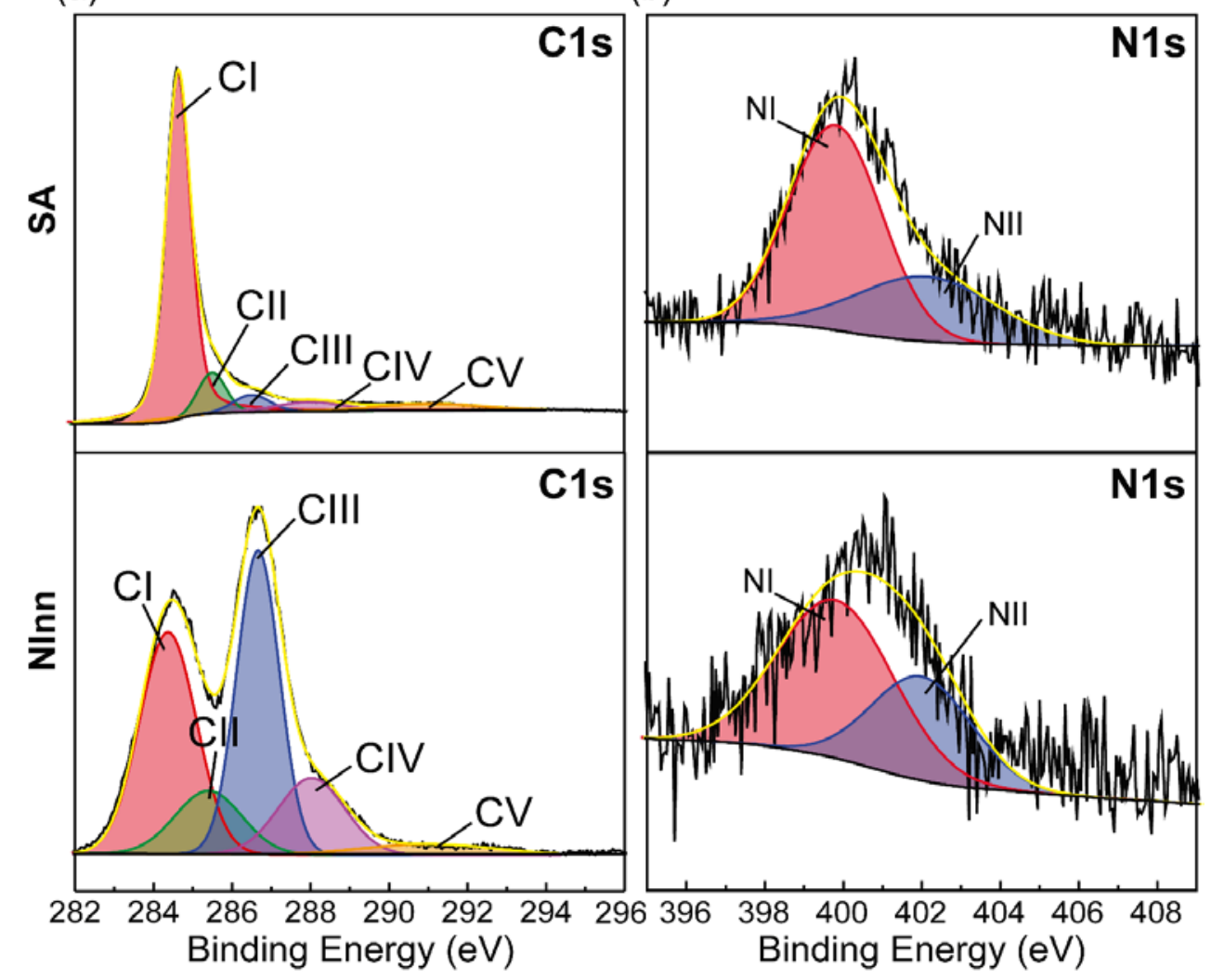

Figure 2. High resolution (a) C1s and (b) N1s XPS spectra of GO powder for Sigma-Aldrich (SA) and NanoInnova (NInn) precursors as indicated. 


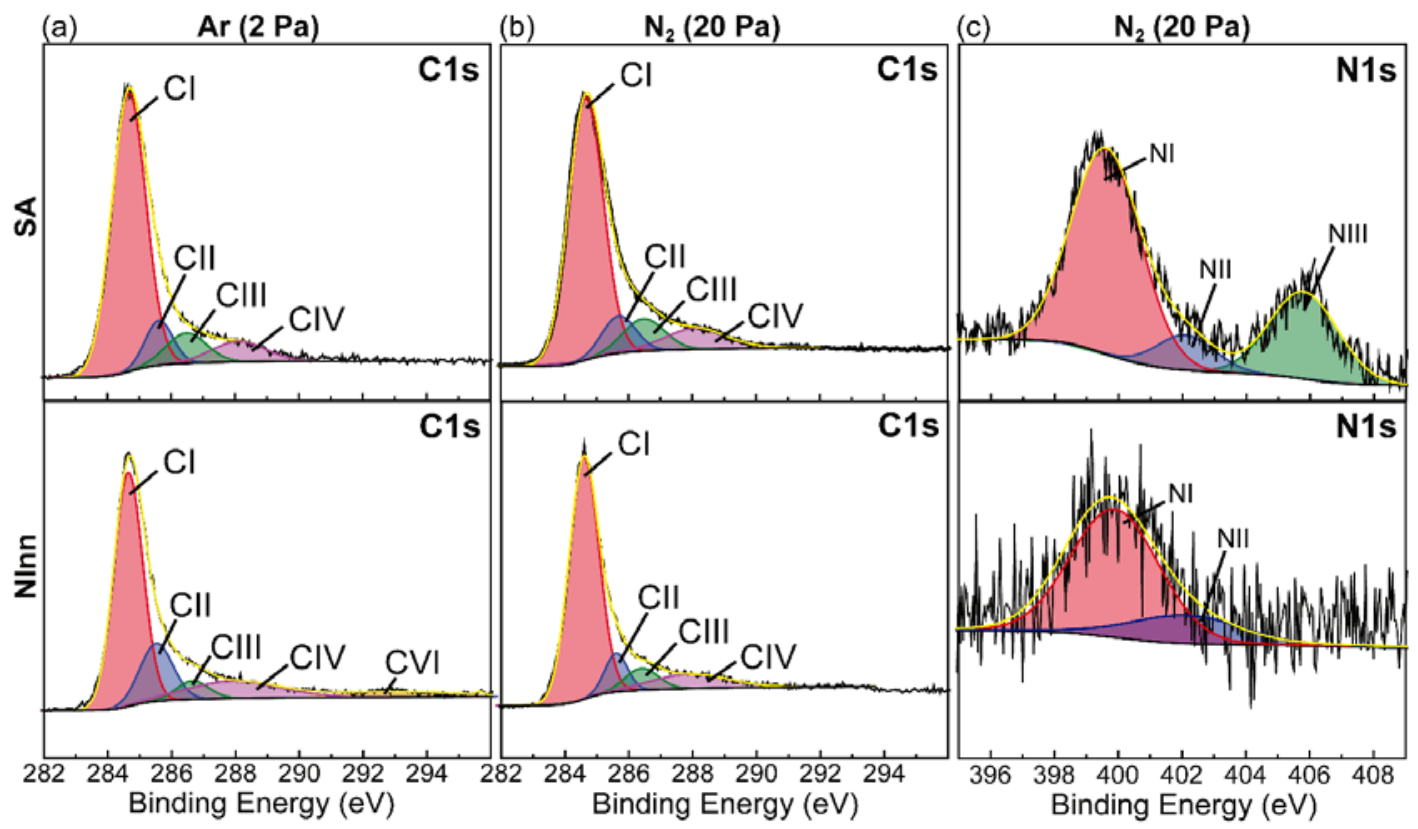

Figure 3. High resolution C1s XPS spectra of GO/Ag nanocomposite films with a ratio Ag/GO of 1 (3 and $6 \% w t$ Ag for SA and NInn precursors, respectively) grown in (a) $\mathrm{Ar}$ (2 Pa) and (b) $\mathrm{N}_{2}$ (20 Pa) ambience. (c) N1s XPS spectra for equivalent films grown in $\mathrm{N}_{2}$ (20 Pa).

Table 1 shows the quantified atomic percentage of Ag present in the samples calculated from the wide scan XPS spectra (not shown). We can see that the amount of Ag increases with the Ag/GO ratio in the target as expected. The fluctuations in the values are likely due to small variations in the target composition caused by aggregation, local variation of the concentration, etc.

\begin{tabular}{|l|c|c|c|c|}
\cline { 2 - 5 } \multicolumn{1}{c|}{} & \multicolumn{4}{c|}{ Quantified Atomic Ag\% } \\
\hline \multirow{2}{*}{ Ratio Ag/GO } & \multicolumn{2}{|c|}{ SA } & \multicolumn{2}{c|}{ NInn } \\
\cline { 2 - 5 } & Ar & $\mathbf{N}_{2}$ & Ar & N$_{2}$ \\
\hline
\end{tabular}




\begin{tabular}{|c|c|c|c|c|}
\hline 0 & 0 & 0 & 0 & 0 \\
\hline $1 / 3$ & 7 & 7 & 14 & 7 \\
\hline 1 & 22 & 10 & 20 & 12 \\
\hline
\end{tabular}

Table 1. Quantified atomic percentages of Ag and $\mathrm{N}_{2}$ extracted from XPS measurements.

A qualitative study of the evolution of the different chemical groups present in GO material was performed by calculating the integrated area of the deconvoluted components in the C1s peaks (Figures 4a, b). We observe a decrease of the integrated area of the CI peak between the powder and dropcasted samples from approximately 77 to $59 \%$ (SA) and from 35 to $25 \%$ (NInn), while the carbon-oxygen peaks grow. Therefore, the powder has a higher degree of reduction compared to the dropcasted one. Thus, the GO precursor seems to oxidize due to the addition of water during the preparation of the dispersions. Graphene oxide is a highly hydrophilic material and is prone to hydrolysis, this would explain the increase of the CII peak intensity, due to the formation of C-OH groups. It has also been reported in the literature that the reaction of GO with water due to heating gives rise to an increase of CO-C groups (CII) [74]. In our case, the dispersions were kept at room temperature all the time. The photo-oxidation of graphene has also been reported during Raman spectroscopy measurements with visible laser irradiation [75]. Moreover, the photoreaction of GO and water due to the interaction with natural UV light can be discarded since it would lead to a decrease of the carbon-oxygen peaks [76]. Instead, the GO-Ag samples prepared by MAPLE present an increase of the CI peak with the amount of silver from around 62 to $70 \%$ (SA) and from 50 to $72 \%$ (NInn), i.e., the C-O peaks (CII-CIV) decrease in intensity. This is independent of the deposition atmosphere. Basically, this means that the C-O bonds are broken due to the interaction of laser photons with the GO sheets contained in the MAPLE target, achieving a partial reduction of the GO in the deposited samples. The most probable reason for the increase of the CI peak with Ag could be caused by the absorption of the UV radiation by Ag NPs which heat and contribute to the chemical reduction of GO [77]. It has also been reported that UV lasers 
produce photochemical effects on the GO due to the absorption of the radiation. This leads to a larger heating and reduction due to photothermal effects $[55,66,78]$. Moreover, the reduction of GO has also been demonstrated by thermal treatments $[79,80]$. For SA precursors, this phenomenon is particularly important for the CII peaks which are associated to epoxy (C-O-C) and hydroxyl (C-OH) groups. Instead, for NInn precursors, the reduction is more prominent for the peaks CIII and CIV associated to carbonyl $(\mathrm{C}=\mathrm{O})$ and carboxyl $(\mathrm{COOH})$ groups. Interestingly, the $\mathrm{C}-\mathrm{O}$ peaks that present a higher degree of reduction are those having a major signal in the dropcasted samples. The use of $\mathrm{N}_{2}$ during deposition improves the reduction of CII peaks for the films produced with both precursors.

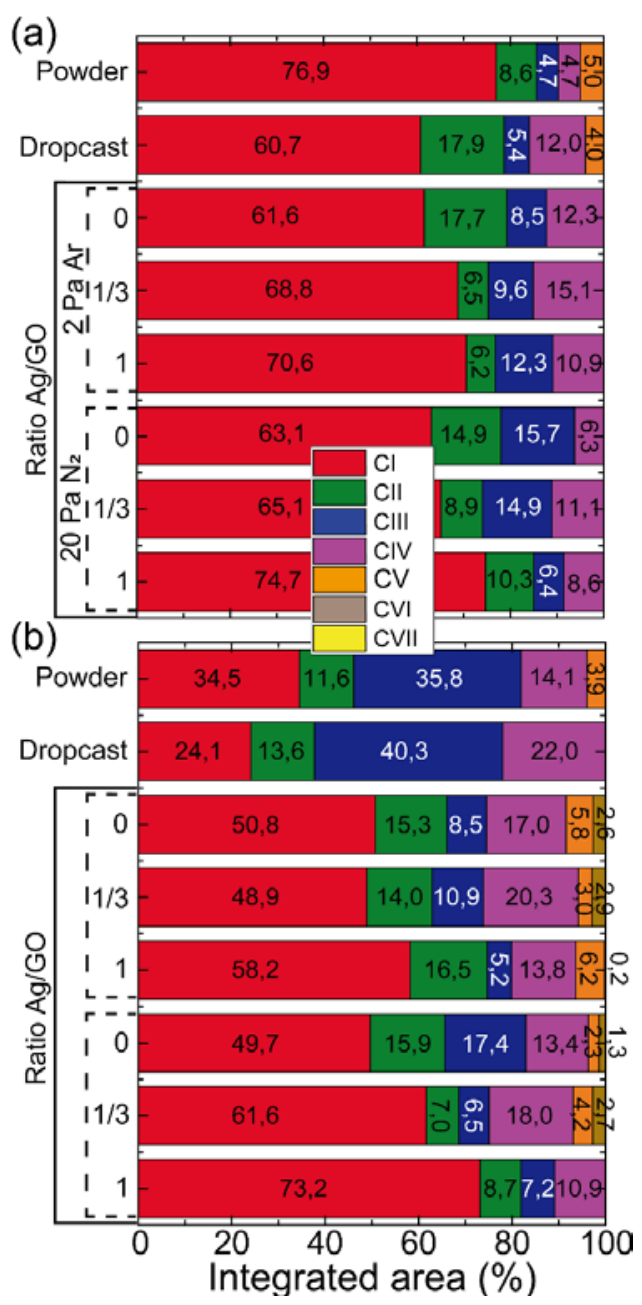


Figure 4. Integrated area of the deconvoluted peaks of GO/Ag nanocomposite films. XPS C1s spectra for (a) SA and (b) NInn precursors.

Figures 5a, b illustrate the integrated area of the deconvoluted components corresponding to the N1s XPS peaks. We can see that the powder and dropcasted GO samples have equivalent ratios for the NI and NII peaks between $\sim 60 / 40$ and $70 / 30$ for GO SA and NInn, respectively. Nevertheless, there is a large difference between the integrated areas of deposited Ag-GO SA and NInn precursors (Figure 5a and 5b). Figure 5a shows that the GO SA sample has a very large integrated area of the NI peak, while the areas of the NII and NIII peaks are much less significant. This indicates that the amount of pyridinic $\mathrm{NO}_{\mathrm{x}}$ groups is low and mostly amine groups are present. Interestingly, the NI peak (amine / pyrrolic $\mathrm{N}$ groups) significantly augments when the amount of silver increases. In addition, the NII peak disappears in the sample with a ratio Ag/GO of 1/3, and the NIII peak area becomes the main contribution. On the other hand, the sample with a ratio Ag/GO of 1 shows similar distribution than GO SA, though the relative contribution of NIII is increased relative to NI. Conversely to GO SA, in the GO films prepared from NInn precursors the NI peak has much smaller integrated area than that of the NII peak. This indicates an increase of pyridinic $\mathrm{NO}_{\mathrm{x}}$ / graphitic (NII) with respect to amine / pyrrolic (NI) groups [81] . The addition of Ag NPs leads to a shift in the intensity of NI and NII peaks, indicating a larger presence of amine / pyrrolic groups with respect to pyridinic $\mathrm{NO}_{\mathrm{x}}$ / graphitic ones. Although typically a mixture of N-containing groups is observed [67], the doping of GO with graphitic $\mathrm{N}$ groups is very interesting to improve its functional properties for fuel cells and electrochemical sensors [82], whereas doping with pyrrolic $\mathrm{N}$ has shown good properties for supercapacitors [83, 84]. In addition, the amount of N-O groups (NII+NIII) decreases with the Ag content. This behavior is completely opposite to the one observed with SA precursors and could be caused by the clearly different chemical structure of the starting GO precursors. It is interesting to elucidate why the reduction of GO and the nitrogen doping seem to increase with the amount of Ag NPs. One of the factors that may contribute to this phenomenon could be related with photothermal interactions. As mentioned before, due to the absorption of UV 
radiation by Ag NPs, their photoactivation leads to an increase of the temperature around them. Hence, they are likely to contribute to the chemical reduction reactions, as well as the $\mathrm{N}$ doping. A similar behavior has been observed in graphene oxide/Ag NPs nanocomposites where GO was reduced under visible light irradiation due to surface plasmon resonance [85].

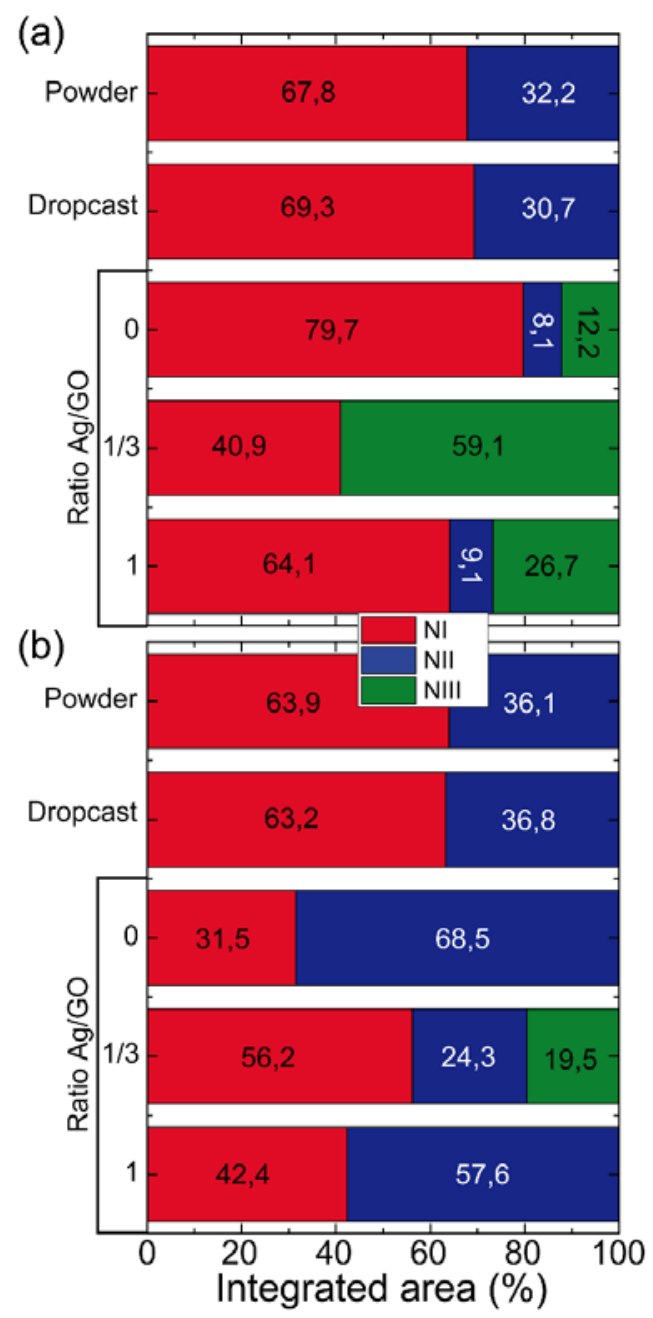

Figure 5. Integrated area of the deconvoluted peaks of GO/Ag nanocomposite films. XPS N1s spectra for (a) SA and (b) NInn precursors. 
Figure $6 \mathrm{a}$ and $6 \mathrm{~b}$ illustrate the ratio between the integrated area of C-O peaks and the total area of the C1s spectra, i.e. C-C and C-O peaks, for the SA and NInn precursors respectively. The ratio for the GO powder sample from the SA precursor is very low at around 0.19 , while it is around 0.65 for the NInn precursors. As mentioned before, this indicates that the SA starting precursor is highly reduced, i.e., it is mostly graphene. Instead, the NInn precursor is more oxidized. In both cases, the ratio $\mathrm{C}-\mathrm{O} /(\mathrm{C}-\mathrm{O}+\mathrm{C}-\mathrm{C})$ increases after mixing with water and performing the dropcast to 0.38 and 0.75 for SA and NInn precursors, respectively. As we mentioned earlier, the rise in the oxidation state could be linked to the reaction of the GO precursor powders with water given the high water affinity of GO. To the extent of our knowledge, this is the first time that this behavior has been reported without any other additional treatment such as thermal annealing or intense illumination [74, 75]. Analyzing the $\mathrm{C}-\mathrm{O} /(\mathrm{C}-\mathrm{O}+\mathrm{C}-\mathrm{C})$ ratio for the GO samples grown in Ar, we can observe that it decreases from $\sim 0.38$ to 0.27 (SA) and from $\sim 0.5$ to 0.4 (NInn) as the amount of silver increases. Also, both precursors experience an equivalent reduction by increasing the amount of Ag. Interestingly, the GO samples grown in $\mathrm{N}_{2}$ present lower degree of reduction using SA precursors (0.37 to 0.32 ) as compared to NInn precursors (0.5 to 0.28). Figure 6c and 6d present the ratio between the N1s spectra and the C1s spectra for SA and NInn precursors, respectively. The N/C ratio is around 0.01 for the GO dropcasted samples from both precursors. This indicates that there is already a slight amount of $\mathrm{N}$ functional groups in the precursor materials, as stated previously. Moreover, the amount of nitrogen incorporated in the samples deposited with a $20 \mathrm{~Pa} \mathrm{~N}_{2}$ ambience increases up to 0.03-0.04 for those prepared from SA precursors. Instead, a larger increase from 0.06 to 0.09 is achieved for the samples prepared from NInn precursors. In summary, GO samples prepared from SA precursors possess rather equivalent C-O bonds under Ar or $\mathrm{N}_{2}$. In contrast, the samples prepared from NInn precursors in $\mathrm{N}_{2}$ have less $\mathrm{C}-\mathrm{O}$ bonds than those grown on Ar. Furthermore, the ratio N/C is around twice than for SA precursors. The incorporation of nitrogen into the structure of GO takes place by interacting with oxygen containing groups [86]. Therefore, more oxygen is lost and more nitrogen is incorporated in the GO NInn samples grown in $\mathrm{N}_{2}$. Despite the amount of oxygen in GO NInn precursors is larger than for SA precursors, the final oxygen 
concentration is similar. This indicates that the structure of GO NInn experiences larger changes in its structure. In addition, the overall N/C ratio grows with the amount of silver.
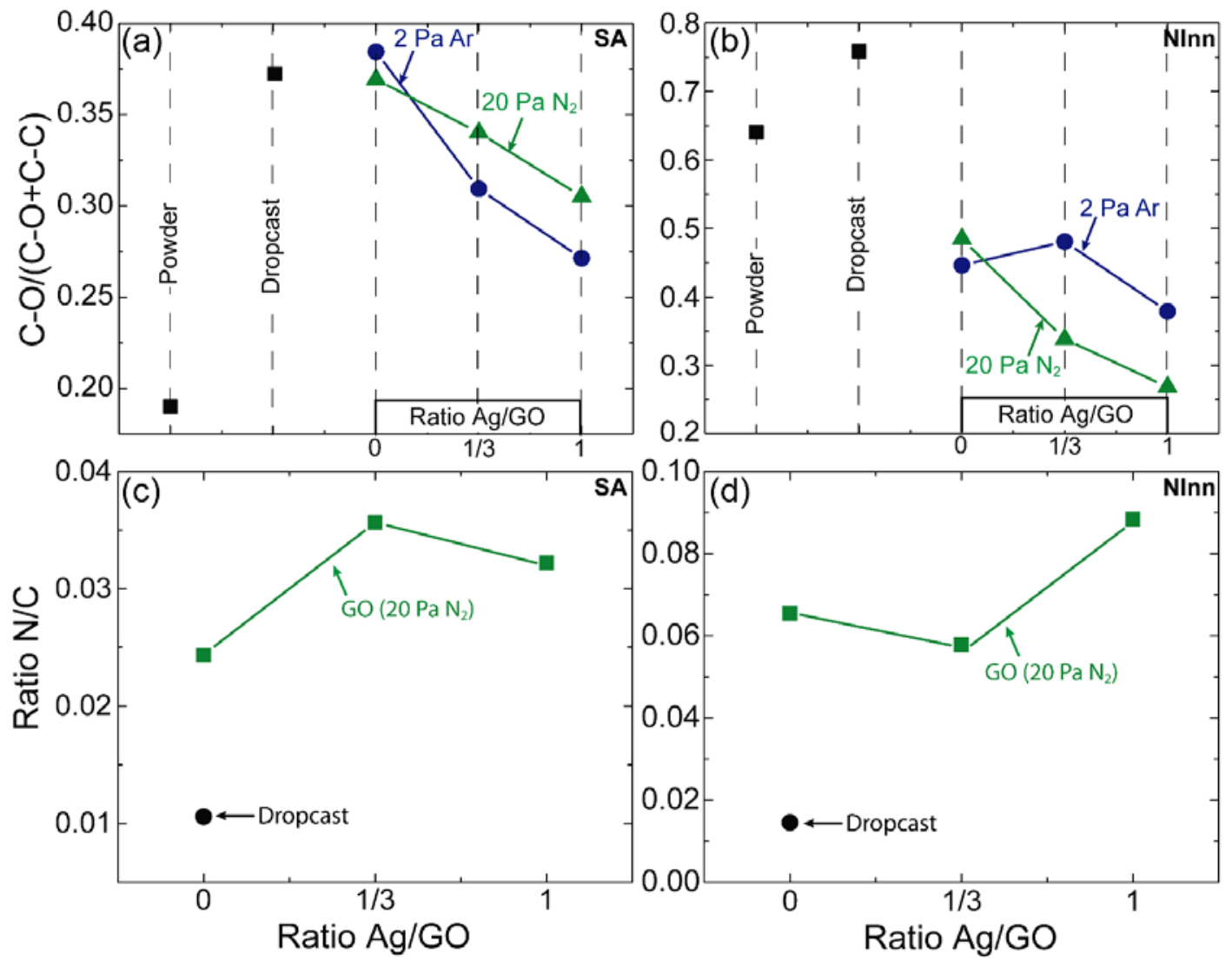

Figure 6. Ratio between the area of XPS C-O peaks and the total area of XPS C1s peaks (C-O+C-C) of GO/Ag nanocomposite films grown from (a) SA and (b) NInn precursors in $\mathrm{Ar}$ (2 Pa) and $\mathrm{N}_{2}$ (20 Pa) ambience as indicated. Powder and dropcast samples are plotted for comparison. Ratio between the total area of N1s and C1s peaks of GO/Ag nanocomposite films grown (c) SA and (d) NInn precursors in $\mathrm{N}_{2}$ (20 Pa) ambience.

\subsection{Functional properties of GO/Ag nanocomposite films}

The optical bandgap of the GO-Ag nanocomposite films has been assessed from Tauc plots (Figure 7). The Tauc plots are for the films prepared from SA and NInn precursors in Ar (Figure 7a and 7b) and $\mathrm{N}_{2}$

Comentario [app1]: No sé si deberíamos incluir las medidas ópticas en este apartado. Al fin y al cabo, el band gap también es un parámetro funcional, ¿no? Estoy dudando...

Comentario [A2]: Tienes razón, queda major aquí 
(Figure 7c and 7d) ambience. The plots were obtained from transmittance spectra reported in Figure S9 and taking into account the film thickness. The films are rather transparent with a transmission in the visible that goes from 15 to $100 \%$ depending on the film thickness and composition. We can see that there is a range of band gaps which is likely related to the non-stoichiometric nature of GO films, i.e., the functional groups present in the platelets are randomly distributed and also every platelet is different from the rest. The band gap range, initially ca. $2.5-3 \mathrm{eV}$, becomes broader and expands to lower values as the $\mathrm{Ag} / \mathrm{GO}$ ratio increases. Furthermore, it seems that the deposition ambience has no noticeable effect on the band gap. It is known that graphene is a zero band gap material although a small one can be opened by doping its structure or through the introduction of structural defects $[87,88]$. On the other hand, the existence of a range of bandgaps (i.e. from 3 to $4.4 \mathrm{eV}$ ) in graphene oxide has been attributed to $\pi-\pi^{*}$ transitions of $\mathrm{C}=\mathrm{C}$ groups and $n-\pi^{*}$ transitions of $\mathrm{C}=\mathrm{O}$ groups [11]. Moreover, it has been also reported that the optical properties of GO highly depend on the ratios of the different oxygen containing functional groups, as well as the oxygen density [89-92]. Consequently, and in concordance with the XPS results, the measured optical properties of the deposited films would indicate the restitution of the graphene domains. Despite that, it should be taken into account that structural defects also increase the absorption at lower energies, which lead to a decrease of the band gap. Therefore, the larger extension of the band gap range to lower energies for GO NInn would be caused by the presence of larger graphitic domains, and the higher concentration of structural defects and nitrogen functional groups. In addition, the concentration of Ag NPs has been directly correlated to an increase of the absorption at higher wavelengths which would explain the lower bandgap values at higher Ag NPs content [77, 93]. 

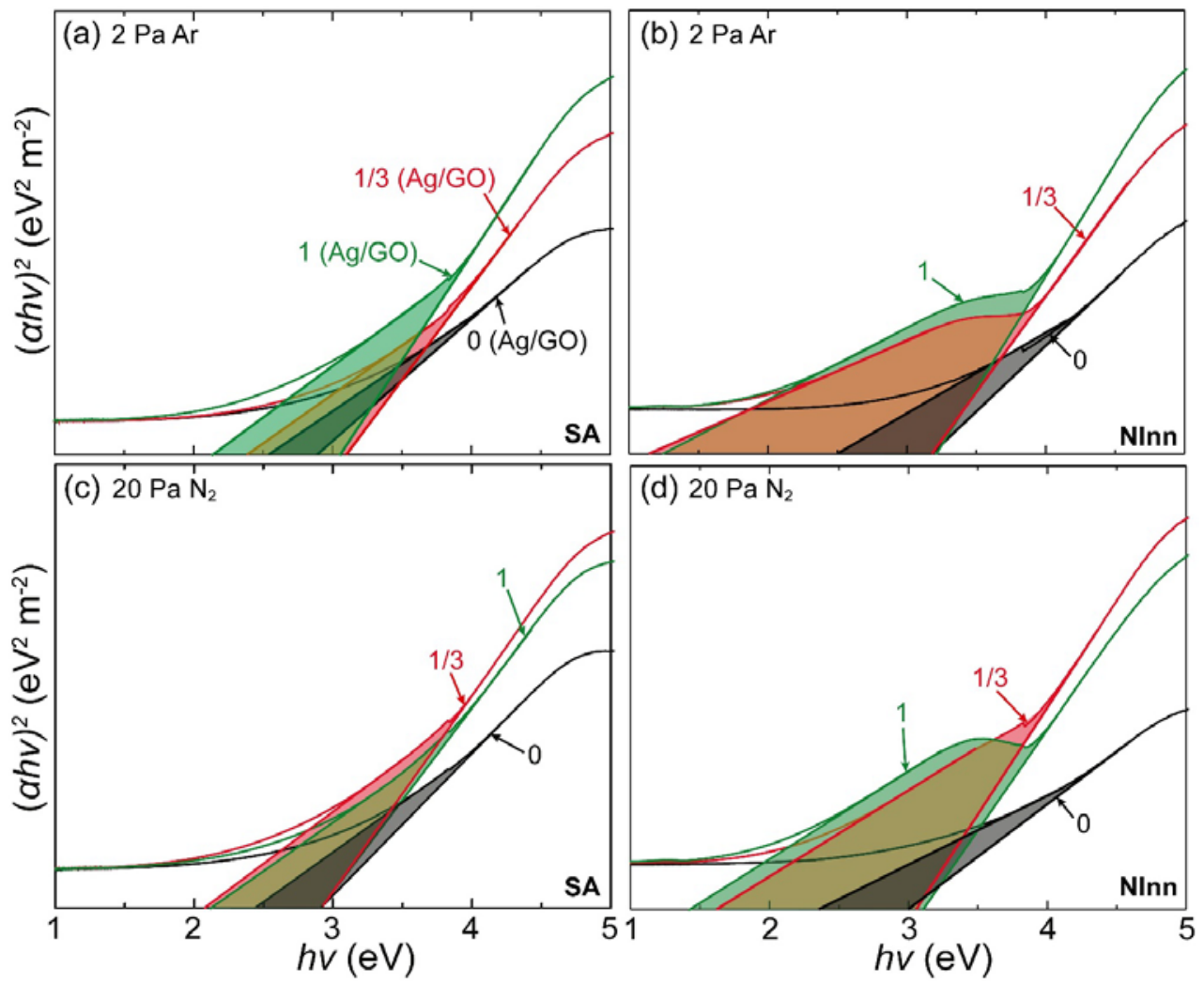

Figure 7. Tauc plots of GO and GO/Ag nanocomposite films grown on quartz substrates by MAPLE in (a) and (b) Ar (2 Pa), and (c) and (d) $\mathrm{N}_{2}$ (20 Pa) ambience from SA and NInn precursors as indicated.

We evaluated the electrochemical performance of Ag/GO nanocomposite films deposited on silicon substrates. Figure 8a presents cyclic voltammetry measurements for films grown from SA precursors. The GO films present resistive behavior and do not show effective charge carrier storage, i.e., the closed area is negligible. This could be caused by a reduced contact between the deposited rGO and the electrolyte, leading to the formation of a poor electric double layer on the GO surface. Instead, we observed a capacitive effect when Ag is added with a ratio of 1 . The films containing lower Ag amounts exhibited unstable behavior during the measurements, probably due to irreversible interactions with the electrolyte, so they are not shown. Probably, the greater inclusion of Ag nanoclusters between rGO sheets leads to their separation and opening of pathways to the electrolyte for reaching much higher 
effective area and, consequently, greater charge accumulation. Recently, Tran et al. also observed an increase of the capacitive response of rGO membranes when decorated with silver nanoparticles [73]. In this work, notable silver oxidation and reduction peaks were present in the voltammograms between 0.2 and $0.5 \mathrm{~V}$. Conversely, our results do not show these oxidation-reduction peaks, possibly confirming the enhancement of the electric double layer formation or pointing to a much greater contribution of the rGO functional groups to the electrochemical performance. It has to be noted that the Ag NPs in Tran et al. work were oxidized to $\mathrm{Ag}_{2} \mathrm{O}$, similarly to our samples (Figure $\mathrm{S} 7$ and $\mathrm{S} 8$ ). Figure $8 \mathrm{~b}$ shows the dependence of the films' volumetric capacitance with the voltage scan rate. The average volumetric capacitance of the electrodes was calculated using equation (1) as follows:

$$
C=\frac{q_{a}+\left|-q_{c}\right|}{2 A d \Delta V}
$$

where $q_{a}$ and $q_{c}$ are the anodic and cathodic charges, respectively, $\mathrm{C}$ is the volumetric capacitance, $\mathrm{A}$ is the geometrical area of the sample in contact with the electrolyte, $\mathrm{d}$ is the film thickness, and $\Delta V$ the voltage range. As observed, the volumetric capacitance decreases with the scan rate, being the maximum value around $12 \mathrm{~F} \mathrm{~cm}^{-3}$ (at $10 \mathrm{mV} \mathrm{s}^{-1}$ scan rate). Due to the rather instability and low volumetric capacitance, it can be concluded that GO (SA) precursor is not the best choice for the fabrication of electrodes. 

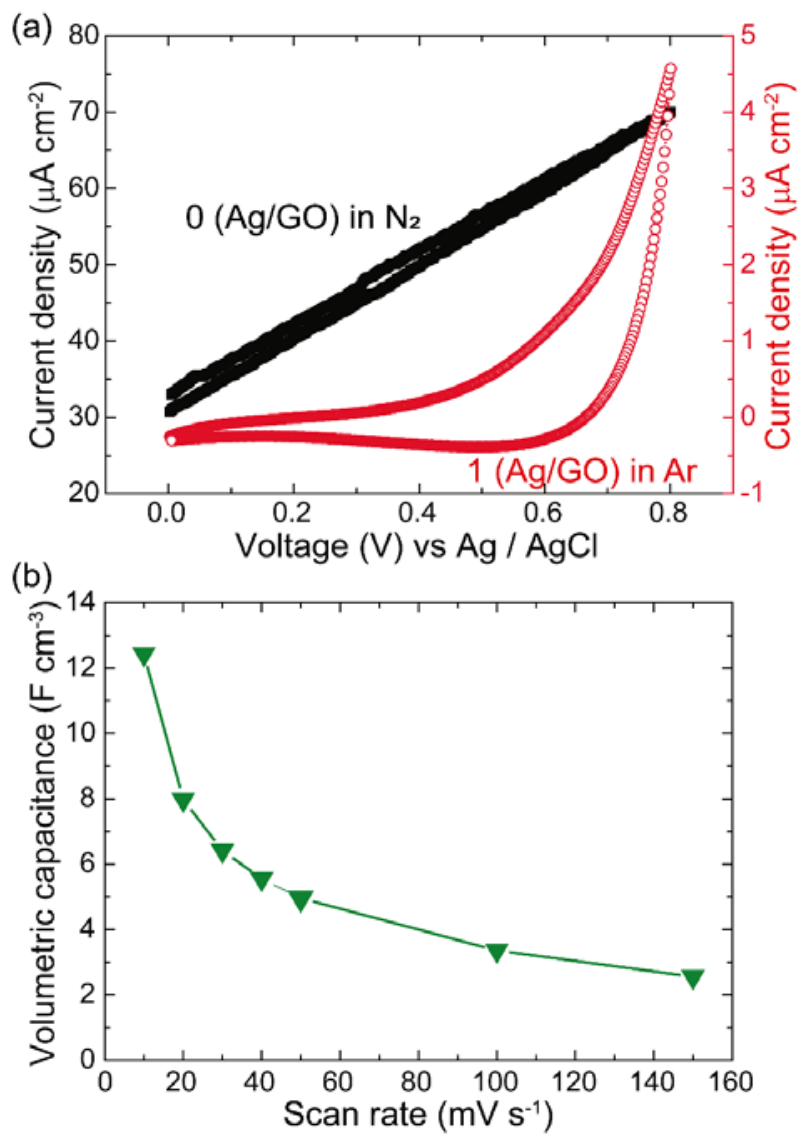

Figure 8. (a) Cyclic voltammograms of $\mathrm{GO}$ and $\mathrm{Ag} / \mathrm{GO}$ films grown from $\mathrm{SA}$ precursors with a ratio of 1 deposited in $\mathrm{N}_{2}$ and $\mathrm{Ar}$, respectively. (b) Volumetric capacitance of the film with a ratio $\mathrm{Ag} / \mathrm{GO}$ of 1 deposited in Ar gas.

Figure 9 shows the cyclic voltammograms and calculated volumetric capacitance of Ag/GO films deposited on silicon substrates using NInn precursors. As compared to the films obtained from SA precursors, the NInn-samples reveal higher electrochemical activity and stability. Thus, even the rGO films (without Ag) show electrochemical storage with a volumetric capacitance similar to the best one obtained with Ag/GO (SA) precursors (ratio of 1). The results clearly point out to an enhancement of the storage capacity with the increase of silver content and, more evidently, nitrogen doping. A maximum 
volumetric capacitance of $70 \mathrm{~F} \mathrm{~cm}^{-3}$ at $10 \mathrm{mV} \mathrm{s}^{-1}$ is obtained in $\mathrm{Ag} / \mathrm{GO}$ films with a ratio of 1 obtained in $\mathrm{N}_{2}$ ambience, corresponding to the maximum nitrogen incorporation and oxygen reduction in rGO structure. Our experimental values are in the same order of magnitude as the ones reported in the literature for rGO $\left(\sim 100 \mathrm{~F} \mathrm{~cm}^{-3}\right)$ [94]. Essentially, surface redox events that take place at the nitrogen functional groups create a pseudocapacitive mechanism which increases the charge storage. This behavior completely aligns with previous works revealing the enhancement of electrochemical storage performance of graphene-based materials caused by nitrogen doping [63, 95-97]. In summary, with these proof-of-concept experiments, it has been demonstrated the feasibility of MAPLE deposition technique for the fabrication of graphene-based hybrid systems for energy storage applications. Since the deposition process is performed at room temperature, this kind of electrodes could be fabricated on polymers for the development of thin and flexible micro-supercapacitors. 
(a)

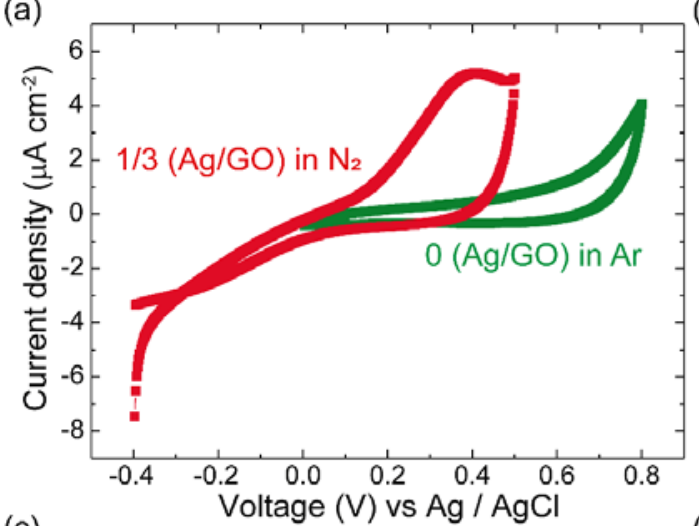

(c)

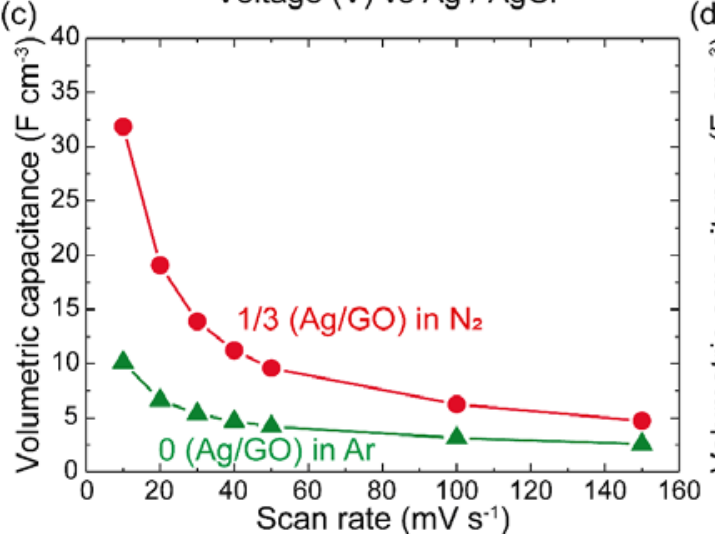

(b)

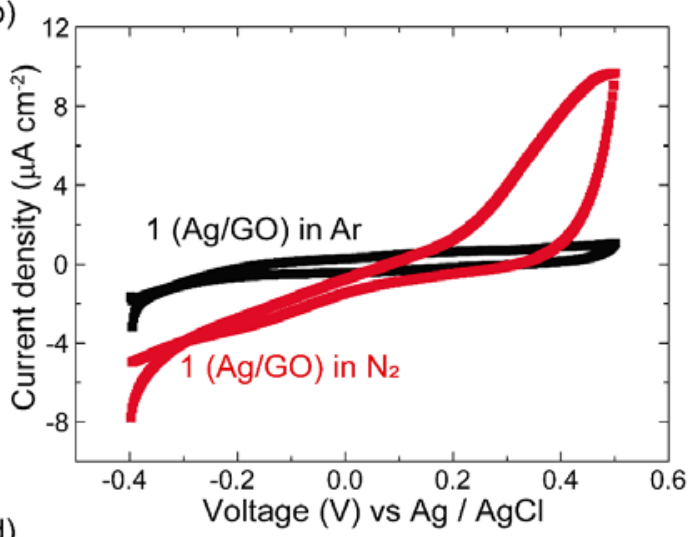

(d)

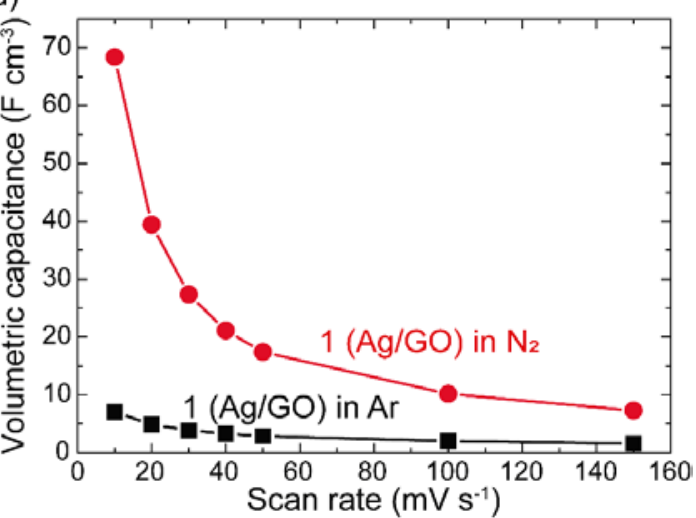

Figure 9. Cyclic voltammograms of (a) GO and Ag/GO films with $1 / 3$ ratio grown from NInn precursors, (b) Ag/GO films with 1 ratio, deposited in Ar and $\mathrm{N}_{2}$. Volumetric capacitance of GO and Ag/GO films with with (c) $1 / 3$ and (d) 1 ratios in $\mathrm{N}_{2}$ and Ar.

\section{CONCLUSIONS}

MAPLE deposition of GO and Ag/GO nanocomposite films has been achieved from water-based frozen targets. It has been demonstrated that Ag/GO films can be deposited on different types of substrates at room temperature. The gas ambience is an experimental parameter which allow versatile tuning of the chemical nature, structure, thickness and functional properties of the films. The interaction between the UV laser photons and the GO nanosheets induce their reduction in all cases. The absorption of laser photon energy by the Ag NPs stands behind the enhanced reduction reactions at larger Ag amounts. The 
degree of GO reduction depends on the precursors material employed. While a strong reduction occurs on epoxy and hydroxyl groups for highly reduced (SA) precursors, the reduction is more prominent for carbonyl and carboxyl groups when highly oxidized (NInn) precursors are used. In addition, irradiation in $\mathrm{N}_{2}$ improves the reduction of epoxy and hydroxyl groups for both precursors. Nitrogen doping shows completely opposite behaviors between both precursors, i.e., amine / pyrrolic groups dominate in films from SA precursors, while besides amine / pyrrolic, graphitic functionalities are more prominent in GO NInn films. The GO NInn precursors experience a larger degree of reduction and N-doping as compared to SA precursors. The addition of Ag shifts the ratio between nitrogen peaks, allowing great tunability of the films properties for applications such as supercapacitors or fuel cells. A range of band gaps is found in our films and this range expands to lower photon energies with the amount of Ag. This is attributed to the restitution of graphene domains through the elimination of oxygen containing groups, as well as the absorption of Ag nanoparticles and the introduction of structural defects in rGO which increase the absorption at lower energies. The electrochemical characterization of the obtained samples shows better performance of the samples fabricated with NInn precursors, revealing an increase of the volumetric capacitance with the content of silver and N-doping.

\section{Acknowledgements}

The authors thank the financial support of the Executive Unit for Financing Higher Education, Research, Development and Innovation of the Romanian Ministry of Education and Scientific Research under the contract PN-III-P2-2.1-PED-2016-1043, in addition to the Spanish Ministry of Economy, Industry and Competitiveness under the projects ENE2014-56109-C3-1-R and ENE2014-56109-C3-3R. ICMAB acknowledges financial support from the Spanish Ministry of Economy and 
Competitiveness, through the "Severo Ochoa" Programme for Centres of Excellence in R\&D (SEV-

2015-0496).

\section{REFERENCES}

[1] A.K. Geim, Graphene: status and prospects, Science, 324 (2009) 1530-1534.

[2] A.K. Geim, K.S. Novoselov, The rise of graphene, Nat. Mater., 6 (2007) 183-191.

[3] D.R. Dreyer, S. Park, C.W. Bielawski, R.S. Ruoff, The chemistry of graphene oxide, Chem. Soc. Rev., 39 (2010) 228-240.

[4] K. Krishnamoorthy, R. Mohan, S.-J. Kim, Graphene oxide as a photocatalytic material, Appl. Phys. Lett., 98 (2011) 244101.

[5] G. Venugopal, K. Krishnamoorthy, R. Mohan, S.-J. Kim, An investigation of the electrical transport properties of graphene-oxide thin films, Mater. Chem. Phys., 132 (2012) 29-33.

[6] H. Dong, W. Gao, F. Yan, H. Ji, H. Ju, Fluorescence resonance energy transfer between quantum dots and graphene oxide for sensing biomolecules, Anal. Chem., 82 (2010) 5511-5517.

[7] S. He, B. Song, D. Li, C. Zhu, W. Qi, Y. Wen, L. Wang, S. Song, H. Fang, C. Fan, A Graphene Nanoprobe for Rapid, Sensitive, and Multicolor Fluorescent DNA Analysis, Adv. Funct. Mater., 20 (2010) 453-459.

[8] K.P. Loh, Q. Bao, G. Eda, M. Chhowalla, Graphene oxide as a chemically tunable platform for optical applications, Nat. Chem., 2 (2010) 1015-1024.

[9] S.E. Yalcin, C. Galande, R. Kappera, H. Yamaguchi, U. Martinez, K.A. Velizhanin, S.K. Doorn, A.M. Dattelbaum, M. Chhowalla, P.M. Ajayan, G. Gupta, A.D. Mohite, Direct Imaging of Charge Transport in Progressively Reduced Graphene Oxide Using Electrostatic Force Microscopy, ACS Nano, 9 (2015) 2981-2988.

[10] X. Wang, X. Li, L. Zhang, Y. Yoon, P.K. Weber, H. Wang, J. Guo, H. Dai, N-Doping of Graphene Through Electrothermal Reactions with Ammonia, Science, 324 (2009) 768-771.

[11] H.-C. Hsu, I. Shown, H.-Y. Wei, Y.-C. Chang, H.-Y. Du, Y.-G. Lin, C.-A. Tseng, C.-H. Wang, L.C. Chen, Y.-C. Lin, K.-H. Chen, Graphene oxide as a promising photocatalyst for $\mathrm{CO}_{2}$ to methanol conversion, Nanoscale, 5 (2013) 262-268.

[12] Y.-G. Lin, C.-K. Lin, J.T. Miller, Y.-K. Hsu, Y.-C. Chen, L.-C. Chen, K.-H. Chen, Photochemically active reduced graphene oxide with controllable oxidation level, RSC Adv., 2 (2012) 11258-11262.

[13] T.-F. Yeh, J.-M. Syu, C. Cheng, T.-H. Chang, H. Teng, Graphite Oxide as a Photocatalyst for Hydrogen Production from Water, Adv. Funct. Mater., 20 (2010) 2255-2262.

[14] T. Schiros, D. Nordlund, L. Pálová, D. Prezzi, L. Zhao, K.S. Kim, U. Wurstbauer, C. Gutiérrez, D. Delongchamp, C. Jaye, D. Fischer, H. Ogasawara, L.G.M. Pettersson, D.R. Reichman, P. Kim, M.S. Hybertsen, A.N. Pasupathy, Connecting Dopant Bond Type with Electronic Structure in N-Doped Graphene, Nano Letters, 12 (2012) 4025-4031.

[15] A.K. Agegnehu, C.-J. Pan, J. Rick, J.-F. Lee, W.-N. Su, B.-J. Hwang, Enhanced hydrogen generation by cocatalytic $\mathrm{Ni}$ and $\mathrm{NiO}$ nanoparticles loaded on graphene oxide sheets, J. Mater. Chem., 22 (2012) 13849-13854.

[16] A. Datcu, L. Duta, A. Perez del Pino, C. Logofatu, C. Luculescu, A. Duta, D. Perniu, E. Gyorgy, One-step preparation of nitrogen doped titanium oxide/Au/reduced graphene oxide composite thin films for photocatalytic applications, RSC Adv., 5 (2015) 49771-49779.

[17] C.-T. Hsieh, W.-Y. Lee, C.-E. Lee, H. Teng, Electrochemical Capacitors Fabricated with Tin Oxide/Graphene Oxide Nanocomposites, J. Phys. Chem. C, 118 (2014) 15146-15153. 
[18] S. Humaira, K.C. Kemp, C. Vimlesh, S.K. Kwang, Graphene- $\mathrm{SnO}_{2}$ composites for highly efficient photocatalytic degradation of methylene blue under sunlight, Nanotechnology, 23 (2012) 355705.

[19] E. György, A. Pérez del Pino, C. Logofatu, C. Cazan, A. Duta, Simultaneous Laser-Induced Reduction and Nitrogen Doping of Graphene Oxide in Titanium Oxide/Graphene Oxide Composites, J. Am. Ceram. Soc., 97 (2014) 2718-2724.

[20] E. György, A. Pérez del Pino, C. Logofatu, A. Duta, L. Isac, Effect of nitrogen doping on wetting and photoactive properties of laser processed zinc oxide-graphene oxide nanocomposite layers, J. Appl. Phys., 116 (2014) 024906.

[21] A. Pérez del Pino, E. György, C. Logofatu, J. Puigmartí-Luis, W. Gao, Laser-induced chemical transformation of graphene oxide-iron oxide nanoparticles composites deposited on polymer substrates, Carbon, 93 (2015) 373-383.

[22] Q. Cheng, J. Tang, J. Ma, H. Zhang, N. Shinya, L.-C. Qin, Graphene and nanostructured $\mathrm{MnO}_{2}$ composite electrodes for supercapacitors, Carbon, 49 (2011) 2917-2925.

[23] F. Meng, J. Li, S.K. Cushing, J. Bright, M. Zhi, J.D. Rowley, Z. Hong, A. Manivannan, A.D. Bristow, N. Wu, Photocatalytic Water Oxidation by Hematite/Reduced Graphene Oxide Composites, ACS Catal., 3 (2013) 746-751.

[24] J. Chen, L. Sun, Y. Cheng, Z. Lu, K. Shao, T. Li, C. Hu, H. Han, Graphene Oxide-Silver Nanocomposite: Novel Agricultural Antifungal Agent against Fusarium graminearum for Crop Disease Prevention, ACS Appl. Mater. Interfaces, 8 (2016) 24057-24070.

[25] B. Song, C. Zhang, G. Zeng, J. Gong, Y. Chang, Y. Jiang, Antibacterial properties and mechanism of graphene oxide-silver nanocomposites as bactericidal agents for water disinfection, Arch. Biochem. Biophys., 604 (2016) 167-176.

[26] A. Soroush, W. Ma, M. Cyr, M.S. Rahaman, B. Asadishad, N. Tufenkji, In SituSilver Decoration on Graphene Oxide-Treated Thin Film Composite Forward Osmosis Membranes: Biocidal Properties and Regeneration Potential, Environ. Sci. Technol. Lett., 3 (2016) 13-18.

[27] X.-F. Sun, J. Qin, P.-F. Xia, B.-B. Guo, C.-M. Yang, C. Song, S.-G. Wang, Graphene oxide-silver nanoparticle membrane for biofouling control and water purification, Chem. Eng. J., 281 (2015) 53-59.

[28] S. Gurunathan, J.W. Han, J.H. Park, E. Kim, Y.J. Choi, D.N. Kwon, J.H. Kim, Reduced graphene oxide-silver nanoparticle nanocomposite: a potential anticancer nanotherapy, Int. J. Nanomedicine, 10 (2015) 6257-6276.

[29] M. Khan, M. Khan, A.H. Al-Marri, A. Al-Warthan, H.Z. Alkhathlan, M.R. Siddiqui, V.L. Nayak, A. Kamal, S.F. Adil, Apoptosis inducing ability of silver decorated highly reduced graphene oxide nanocomposites in A549 lung cancer, Int. J. Nanomedicine, 11 (2016) 873-883.

[30] A.M. Golsheikh, N.M. Huang, H.N. Lim, R. Zakaria, One-pot sonochemical synthesis of reduced graphene oxide uniformly decorated with ultrafine silver nanoparticles for non-enzymatic detection of H2O2and optical detection of mercury ions, RSC Adv., 4 (2014) 36401-36411.

[31] A.C. Joshi, G.B. Markad, S.K. Haram, Rudimentary simple method for the decoration of graphene oxide with silver nanoparticles: Their application for the amperometric detection of glucose in the human blood samples, Electrochim. Acta, 161 (2015) 108-114.

[32] A.a.M. Noor, P. Rameshkumar, N. Yusoff, H.N. Ming, M.S. Sajab, Microwave synthesis of reduced graphene oxide decorated with silver nanoparticles for electrochemical determination of 4nitrophenol, Ceram. Int., 42 (2016) 18813-18820.

[33] J. Wang, X. Wang, S. Wu, J. Song, Y. Zhao, Y. Ge, C. Meng, Fabrication of highly catalytic silver nanoclusters/graphene oxide nanocomposite as nanotag for sensitive electrochemical immunoassay, Anal. Chim. Acta, 906 (2016) 80-88.

[34] A.K. Yagati, Y. Choi, J. Park, J.W. Choi, H.S. Jun, S. Cho, Silver nanoflower-reduced graphene oxide composite based micro-disk electrode for insulin detection in serum, Biosens. Bioelectron., 80 (2016) 307-314.

[35] D. Koushik, S. Sen Gupta, S.M. Maliyekkal, T. Pradeep, Rapid dehalogenation of pesticides and organics at the interface of reduced graphene oxide-silver nanocomposite, J. Hazard Mater., 308 (2016) 192-198. 
[36] Q. Li, P. Hai, Rapid microwave-assisted synthesis of silver decorated-reduced graphene oxide nanoparticles with enhanced photocatalytic activity under visible light, Materials Science in Semiconductor Processing, 22 (2014) 16-20.

[37] T.V.M. Sreekanth, M.-J. Jung, I.-Y. Eom, Green synthesis of silver nanoparticles, decorated on graphene oxide nanosheets and their catalytic activity, Appl. Surf. Sci., 361 (2016) 102-106.

[38] H.-W. Tien, Y.-L. Huang, S.-Y. Yang, J.-Y. Wang, C.-C.M. Ma, The production of graphene nanosheets decorated with silver nanoparticles for use in transparent, conductive films, Carbon, 49 (2011) 1550-1560.

[39] P.R. Ilango, R. Gnanamuthu, Y.N. Jo, C.W. Lee, Design and electrochemical investigation of a novel graphene oxide-silver joint conductive agent on LiFePO4 cathodes in rechargeable lithium-ion batteries, J. Industrial Eng. Chem., 36 (2016) 121-124.

[40] K. Sarkar, K.J. Sarkar, P. Banerji, Synthesis of graphene oxide-silver nanocomposite with photochemically grown silver nanoparticles to use as a channel material in thin film field effect transistors, RSC Adv., 5 (2015) 107811-107821.

[41] L.T. Soo, K.S. Loh, A.B. Mohamad, W.R.W. Daud, W.Y. Wong, Synthesis of silver/nitrogendoped reduced graphene oxide through a one-step thermal solid-state reaction for oxygen reduction in an alkaline medium, J. Power Sources, 324 (2016) 412-420.

[42] Y. Zhou, J. Yang, X. Cheng, N. Zhao, H. Sun, D. Li, Transparent and conductive reduced graphene oxide/silver nanoparticles multilayer film obtained by electrical self-assembly process with graphene oxide sheets and silver colloid, RSC Adv., 3 (2013) 3391.

[43] M. Yu, P. Liu, S. Zhang, J. Liu, J. An, S. Li, Preparation of graphene-Ag composites and their application for electrochemical detection of chloride, Materials Research Bulletin, 47 (2012) 3206-3210. [44] S. Stankovich, D.A. Dikin, R.D. Piner, K.A. Kohlhaas, A. Kleinhammes, Y. Jia, Y. Wu, S.T. Nguyen, R.S. Ruoff, Synthesis of graphene-based nanosheets via chemical reduction of exfoliated graphite oxide, Carbon, 45 (2007) 1558-1565.

[45] S. Pei, H.-M. Cheng, The reduction of graphene oxide, Carbon, 50 (2012) 3210-3228.

[46] A. Piqué, The Matrix-Assisted Pulsed Laser Evaporation (MAPLE) process: origins and future directions, Appl. Phys. A, 105 (2011) 517-528.

[47] J.M. Fitz-Gerald, G. Jennings, R. Johnson, C.L. Fraser, Matrix assisted pulsed laser deposition of light emitting polymer thin films, Appl. Phys. A, 80 (2005) 1109-1112.

[48] W. Ge, Q. Yu, G.P. Lopez, A.D. Stiff-Roberts, Antimicrobial oligo(p-phenylene-ethynylene) film deposited by resonant infrared matrix-assisted pulsed laser evaporation, Colloids Surf. B Biointerfaces, 116 (2014) 786-792.

[49] B.R. Ringeisen, D.B. Chrisey, A. Piqué, H.D. Young, R. Modi, M. Bucaro, J. Jones-Meehan, B.J. Spargo, Generation of mesoscopic patterns of viable Escherichia coli by ambient laser transfer, Biomaterials, 23 (2002) 161-166.

[50] P.K. Wu, B.R. Ringeisen, D.B. Krizman, C.G. Frondoza, M. Brooks, D.M. Bubb, R.C.Y. Auyeung, A. Piqué, B. Spargo, R.A. McGill, D.B. Chrisey, Laser transfer of biomaterials: Matrix-assisted pulsed laser evaporation (MAPLE) and MAPLE Direct Write, Rev. Sci. Instruments, 74 (2003) 2546.

[51] Y. Guo, A. Morozov, D. Schneider, J.W. Chung, C. Zhang, M. Waldmann, N. Yao, G. Fytas, C.B. Arnold, R.D. Priestley, Ultrastable nanostructured polymer glasses, Nat. Mater., 11 (2012) 337-343.

[52] A.P. Caricato, M. Epifani, M. Martino, F. Romano, R. Rella, A. Taurino, T. Tunno, D. Valerini, MAPLE deposition and characterization of $\mathrm{SnO}_{2}$ colloidal nanoparticle thin films, J. Phys. D Appl. Phys., 42 (2009) 095105.

[53] C.N. Hunter, M.H. Check, J.E. Bultman, A.A. Voevodin, Development of matrix-assisted pulsed laser evaporation (MAPLE) for deposition of disperse films of carbon nanoparticles and gold/nanoparticle composite films, Surf. and Coat. Technol., 203 (2008) 300-306.

[54] Á. Pérez del Pino, E. György, L. Cabana, B. Ballesteros, G. Tobias, Deposition of functionalized single wall carbon nanotubes through matrix assisted pulsed laser evaporation, Carbon, 50 (2012) 44504458. 
[55] A. Pérez del Pino, E. György, C. Logofatu, A. Duta, Study of the deposition of graphene oxide by matrix-assisted pulsed laser evaporation, J. Phys. D Appl. Phys., 46 (2013) 505309.

[56] J. Tauc, R. Grigorovici, A. Vancu, Optical Properties and Electronic Structure of Amorphous Germanium, physica status solidi (b), 15 (1966) 627-637.

[57] E.A. Davis, N.F. Mott, Conduction in non-crystalline systems V. Conductivity, optical absorption and photoconductivity in amorphous semiconductors, Philosophical Magazine, 22 (1970) 0903-0922.

[58] B. Zhang, L. Li, Z. Wang, S. Xie, Y. Zhang, Y. Shen, M. Yu, B. Deng, Q. Huang, C. Fan, J. Li, Radiation induced reduction: an effective and clean route to synthesize functionalized graphene, J. Mater. Chem., 22 (2012) 7775-7781.

[59] S. Pei, J. Zhao, J. Du, W. Ren, H.-M. Cheng, Direct reduction of graphene oxide films into highly conductive and flexible graphene films by hydrohalic acids, Carbon, 48 (2010) 4466-4474.

[60] T.I.T. Okpalugo, P. Papakonstantinou, H. Murphy, J. McLaughlin, N.M.D. Brown, High resolution XPS characterization of chemical functionalised MWCNTs and SWCNTs, Carbon, 43 (2005) 153-161.

[61] S. Seo, Y. Yoon, J. Lee, Y. Park, H. Lee, Nitrogen-Doped Partially Reduced Graphene Oxide Rewritable Nonvolatile Memory, ACS Nano, 7 (2013) 3607-3615.

[62] D. Kepić, S. Sandoval, Á.P.d. Pino, E. György, L. Cabana, B. Ballesteros, G. Tobias, Nanosecond Laser-Assisted Nitrogen Doping of Graphene Oxide Dispersions, ChemPhysChem, (2017).

[63] H. Nolan, B. Mendoza-Sanchez, N. Ashok Kumar, N. McEvoy, S. O'Brien, V. Nicolosi, G.S. Duesberg, Nitrogen-doped reduced graphene oxide electrodes for electrochemical supercapacitors, Phys. Chem. Chem. Phys., 16 (2014) 2280-2284.

[64] Y. Yamada, J. Kim, S. Matsuo, S. Sato, Nitrogen-containing graphene analyzed by X-ray photoelectron spectroscopy, Carbon, 70 (2014) 59-74.

[65] A.P. Dementjev, A. de Graaf, M.C.M. van de Sanden, K.I. Maslakov, A.V. Naumkin, A.A. Serov, $\mathrm{X}$-Ray photoelectron spectroscopy reference data for identification of the $\mathrm{C}_{3} \mathrm{~N}_{4}$ phase in carbonnitrogen films, Diamond and Related Materials, 9 (2000) 1904-1907.

[66] S.M. O’Malley, J. Tomko, A.P.d. Pino, C. Logofatu, E. György, Resonant Infrared and Ultraviolet Matrix-Assisted Pulsed Laser Evaporation of Titanium Oxide/Graphene Oxide Composites: A Comparative Study, The Journal of Physical Chemistry C, 118 (2014) 27911-27919.

[67] Y. Sun, C. Li, G. Shi, Nanoporous nitrogen doped carbon modified graphene as electrocatalyst for oxygen reduction reaction, J. Mater. Chem., 22 (2012) 12810-12816.

[68] A. Adenier, E. Cabet-Deliry, A. Chaussé, S. Griveau, F. Mercier, J. Pinson, C. Vautrin-Ul, Grafting of Nitrophenyl Groups on Carbon and Metallic Surfaces without Electrochemical Induction, Chem. Mater., 17 (2005) 491-501.

[69] P. Mendes, M. Belloni, M. Ashworth, C. Hardy, K. Nikitin, D. Fitzmaurice, K. Critchley, S. Evans, J. Preece, A novel example of X-ray-radiation-induced chemical reduction of an aromatic nitro-groupcontaining thin film on SiO2 to an aromatic amine film, Chemphyschem, 4 (2003) 884-889.

[70] A. Barrie, N.E. Christensen, High-resolution x-ray photoemission spectra of silver, Phys. Rev. B, 14 (1976) 2442-2447.

[71] G. Zhang, S. Sun, D. Yang, J.-P. Dodelet, E. Sacher, The surface analytical characterization of carbon fibers functionalized by $\mathrm{H}_{2} \mathrm{SO}_{4} / \mathrm{HNO}_{3}$ treatment, Carbon, 46 (2008) 196-205.

[72] L. Shi, L. Liang, J. Ma, F. Wang, J. Sun, Enhanced photocatalytic activity over the $\mathrm{Ag}_{2} \mathrm{O}-\mathrm{g}-\mathrm{C}_{3} \mathrm{~N}_{4}$ composite under visible light, Catal. Sci. Technol., 4 (2014) 758.

[73] M.-H. Tran, H.K. Jeong, Synthesis and characterization of silver nanoparticles doped reduced graphene oxide, Chem. Phys. Lett., 630 (2015) 80-85.

[74] M. Acik, C. Mattevi, C. Gong, G. Lee, K. Cho, M. Chhowalla, Y.J. Chabal, The role of intercalated water in multilayered graphene oxide, ACS Nano, 4 (2010) 5861-5868.

[75] N. Mitoma, R. Nouchi, K. Tanigaki, Photo-oxidation of Graphene in the Presence of Water, J. Phys. Chem. C, 117 (2013) 1453-1456.

[76] Y. Matsumoto, M. Koinuma, S. Ida, S. Hayami, T. Taniguchi, K. Hatakeyama, H. Tateishi, Y. Watanabe, S. Amano, Photoreaction of Graphene Oxide Nanosheets in Water, J. Phys. Chem. C, 115 (2011) 19280-19286. 
[77] N.T. Lan, D.T. Chi, N.X. Dinh, N.D. Hung, H. Lan, P.A. Tuan, L.H. Thang, N.N. Trung, N.Q. Hoa, T.Q. Huy, N.V. Quy, T.-T. Duong, V.N. Phan, A.-T. Le, Photochemical decoration of silver nanoparticles on graphene oxide nanosheets and their optical characterization, J. Alloys Compd., 615 (2014) 843-848.

[78] V. Le Borgne, H. Bazi, T. Hayashi, Y.A. Kim, M. Endo, M.A. El Khakani, Hydrogen-assisted pulsed KrF-laser irradiation for the in situ photoreduction of graphene oxide films, Carbon, 77 (2014) 857-867.

[79] R. Larciprete, S. Fabris, T. Sun, P. Lacovig, A. Baraldi, S. Lizzit, Dual Path Mechanism in the Thermal Reduction of Graphene Oxide, Journal of the American Chemical Society, 133 (2011) 1731517321.

[80] X. Liu, H. Kim, L.J. Guo, Optimization of thermally reduced graphene oxide for an efficient hole transport layer in polymer solar cells, Organic Electronics, 14 (2013) 591-598.

[81] T. Xing, Y. Zheng, L.H. Li, B.C.C. Cowie, D. Gunzelmann, S.Z. Qiao, S. Huang, Y. Chen, Observation of Active Sites for Oxygen Reduction Reaction on Nitrogen-Doped Multilayer Graphene, ACS Nano, 8 (2014) 6856-6862.

[82] T.N. Huan, T. Van Khai, Y. Kang, K.B. Shim, H. Chung, Enhancement of quaternary nitrogen doping of graphene oxide via chemical reduction prior to thermal annealing and an investigation of its electrochemical properties, J. Mater. Chem., 22 (2012) 14756-14762.

[83] F.M. Hassan, V. Chabot, J. Li, B.K. Kim, L. Ricardez-Sandoval, A. Yu, Pyrrolic-structure enriched nitrogen doped graphene for highly efficient next generation supercapacitors, J. Mater. Chem. A, 1 (2013) 2904.

[84] S.M. Unni, S. Devulapally, N. Karjule, S. Kurungot, Graphene enriched with pyrrolic coordination of the doped nitrogen as an efficient metal-free electrocatalyst for oxygen reduction, J. Mater. Chem., 22 (2012) 23506.

[85] T. Wu, S. Liu, Y. Luo, W. Lu, L. Wang, X. Sun, Surface plasmon resonance-induced visible light photocatalytic reduction of graphene oxide: using Ag nanoparticles as a plasmonic photocatalyst, Nanoscale, 3 (2011) 2142-2144.

[86] B. Jiang, C. Tian, L. Wang, L. Sun, C. Chen, X. Nong, Y. Qiao, H. Fu, Highly concentrated, stable nitrogen-doped graphene for supercapacitors: Simultaneous doping and reduction, Appl. Surf. Sci., 258 (2012) 3438-3443.

[87] X. Fan, Z. Shen, A.Q. Liu, J.L. Kuo, Band gap opening of graphene by doping small boron nitride domains, Nanoscale, 4 (2012) 2157-2165.

[88] C. Soo Park, Y. Zhao, J.-H. Lee, D. Whang, Y. Shon, Y.-H. Song, C. Jin Lee, Tunable bandgap of a single layer graphene doped by the manganese oxide using the electrochemical doping, Appl. Physi. Lett., 102 (2013) 032106.

[89] P.K. Narayanam, K. Sankaran, Optical behaviour of functional groups of graphene oxide, Mater. Res. Express, 3 (2016) 105604.

[90] M.A. Velasco-Soto, S.A. Pérez-García, J. Alvarez-Quintana, Y. Cao, L. Nyborg, L. Licea-Jiménez, Selective band gap manipulation of graphene oxide by its reduction with mild reagents, Carbon, 93 (2015) 967-973.

[91] H. Huang, Z. Li, J. She, W. Wang, Oxygen density dependent band gap of reduced graphene oxide, J. Appl. Phys., 111 (2012) 054317.

[92] H.K. Jeong, M.H. Jin, K.P. So, S.C. Lim, Y.H. Lee, Tailoring the characteristics of graphite oxides by different oxidation times, Journal of Physics D: Applied Physics, 42 (2009) 065418.

[93] S. Biswas, A.K. Kole, C.S. Tiwary, P. Kumbhakar, Enhanced nonlinear optical properties of graphene oxide-silver nanocomposites measured by Z-scan technique, RSC Adv., 6 (2016) 1031910325.

[94] Q. Wang, J. Yan, Z. Fan, Carbon materials for high volumetric performance supercapacitors: design, progress, challenges and opportunities, Energy Environ. Sci., 9 (2016) 729-762. 
[95] Z. Wen, X. Wang, S. Mao, Z. Bo, H. Kim, S. Cui, G. Lu, X. Feng, J. Chen, Crumpled NitrogenDoped Graphene Nanosheets with Ultrahigh Pore Volume for High-Performance Supercapacitor, Adv. Mater., 24 (2012) 5610-5616.

[96] Y. Qiu, X. Zhang, S. Yang, High performance supercapacitors based on highly conductive nitrogen-doped graphene sheets, Phys. Chem. Chem. Phys., 13 (2011) 12554-12558.

[97] T. Lin, I.W. Chen, F. Liu, C. Yang, H. Bi, F. Xu, F. Huang, Nitrogen-doped mesoporous carbon of extraordinary capacitance for electrochemical energy storage, Science, 350 (2015) 1508-1513. 